\title{
PROTEÇÃO JURÍDICA DOS DIREITOS À PRIVACIDADE E À INTIMIDADE DIANTE DAS NOVAS TECNOLOGIAS INFORMÁTICAS
}

\author{
LEGAL PROTECTION OF THE RIGHTS PRIVACY AND INTIMACY IN THE FACE OF \\ NEW INFORMATICS TECHNOLOGIES
}

Lucas Gonçalves da Silva

Jacqueline Taís Menezes Paez Cury ${ }^{2}$

\section{Resumo}

A privacidade e a intimidade constituem direitos de personalidade que se aproximam da ideia de segredo da pessoa humana. Salienta-se que pairam dúvidas sobre o alcance da proteção destes direitos no âmbito digital, com isso, o presente trabalho tem por objetivo analisar se estes tradicionais direitos previstos na $\mathrm{CF} / 88$, conseguem fornecer um manto de proteção aos dados pessoais nos meios informáticos ou se há necessidade da consolidação de um novel direito a ser inserido na Carta Magna. A hipótese deste trabalho, pauta-se no reconhecimento do direito fundamental à proteção de dados pessoais disponíveis na internet como um novo, específico e independente direito na lista das garantias da Constituição Federal. Para isso, será utilizada como metodologia a pesquisa qualitativa, por meio da leitura, análise doutrinária, legislativa e jurisprudencial particularizada, sínteses das informações contidas em vários livros jurídicos com explanação e discussão de algumas opiniões doutrinárias sobre o tema.

Palavras-chave: Privacidade; Intimidade; Dados pessoais; Meios informáticos.

\begin{abstract}
Privacy and intimacy are personality rights that approach the idea of a secret of the human person. It should be noted that doubts are common about the scope of the protection of these rights in the digital field, thus, the present work aims to examine whether these traditional rights provided for in the $\mathrm{CF} / 88$ are able to provide a maintenance of personal data on the computer media or whether there is a need for the consolidation of a novel right to be inserted into the Constitution. The hypothesis of this work is based on the recognition of them

\footnotetext{
${ }^{1}$ Professor do Mestrado e da Graduação em Direito na Universidade Federal de Sergipe (UFS). Orientador da Mestranda Jacqueline T. M. P. Cury. E-mail:lucasgs@uol.com.br.

O presente trabalho foi realizado com o apoio da Coordenação de Aperfeiçoamento de Pessoal de Nível Superior - (Brasil) CAPES - Código de Financiamento 001.

2 Mestranda em Direito pela Universidade Federal de Sergipe. Pós-Graduada em Direito Constitucional e Administrativo pela Escola Paulista de Direito. Coordenadora do Aracaju Legal Hackers e membro do IBDEE e da Internet Society. Servidora do TJSE.
} 
fundamental right to the protection of personal data available on the Internet as a new, specific and independent right in the list of guarantees of the Federal Constitution. For this, qualitative research was used as a methodology, through reading, doctrinal, legislative and jurisprudential analysis, summaries of information contained in several legal books with explanation and discussion of some doctrinal opinions on the subject.

Keywords: Privacy; Intimacy; Personal data; Informatics media.

\section{INTRODUÇÃO}

Com o advento das novas tecnologias, surge uma preocupação constante a respeito da proteção das informações e dos dados pessoais, pois uma vez divulgados em ínfimo lapso temporal chegam a ser compartilhados a nível global. Há quem duvide que atualmente exista a privacidade e a intimidade, pois estes direitos não possuem uma fronteira que os definam com exatidão quanto ao alcance da proteção à privacidade e a inviolabilidade da intimidade das informações e dados pessoais contidos na internet.

O objetivo do presente artigo é justamente analisar qual a proteção jurídica proporcionada à privacidade e à intimidade dos dados pessoais nos meios informáticos, a fim de esclarecer se essa tutela é uma extensão dos direitos fundamentais ou se seria um novo direito independente dos direitos à privacidade e à intimidade.

A hipótese deste trabalho, pauta-se no reconhecimento do direito fundamental à proteção de dados pessoais disponíveis na internet como um novo, específico e independente direito na lista das garantias da Constituição Federal.

Para isso, será adotada como metodologia a pesquisa bibliográfica qualitativa, por meio da leitura, análise doutrinária, legislativa e jurisprudencial particularizada, sínteses das informações contidas em vários livros jurídicos com explanação e discussão de algumas opiniões doutrinárias sobre o tema.

Desta forma, entende-se que o desenvolvimento do tema proposto expressa relevância jurídica e acadêmica, porque traz uma contribuição no sentido de fornecer conhecimento sobre as novas legislações infraconstitucionais e entendimentos da jurisprudência, como instrumentos 
de reforço à tutela da privacidade e da intimidade aos dados pessoais contidos em dispositivos eletrônicos e fornecidos a empresas no ambiente virtual.

\section{A GÊNESE DA PRIVACIDADE E DA INTIMIDADE}

A evolução destes direitos, com o desenvolvimento doutrinário e jurisprudencial na Europa e nos Estados Unidos durante o século XIX, obteve reconhecimento após a primeira metade do século XX. "Um marco importante no direito europeu foi a Revolução francesa com sua Declaração Universal dos Direitos do Homem e do Cidadão em 1789 e o Código Civil de Napoleão em 1804” (ROBL FILHO, 2010).

Fernando Herrero Tejedor citado por Pereira (2006), assevera que o "direito à intimidade" deriva da expressão "the right to be let alone" elaborado por Cooley na obra The Elements of Torts, datada de 1873. A tradução literal para o a língua portuguesa significa "direito de ser deixado só" e para o idioma castelhano compreende o "direito a ser deixado em paz", isto é, como a possibilidade do indivíduo de viver em tranquilidade e em solidão (PEREIRA, 2006).

Já Anderson Schreiber (2013), aponta como fonte da supracitada expressão em inglês, o célebre artigo The Right to Privacy, publicado em 1890, na revista jurídica da faculdade americana Harvard escrito pelos advogados Samuel Warren e Louis Brandeis, motivados pelo destaque exagerado que os jornais de Boston reservavam à vida social da mulher de Samuel. Esse artigo explica o cunho individualista alcançado pelo direito à privacidade, apresentado como um direito a ser deixado em paz consigo.

$\mathrm{O}$ art. 12 da Declaração Universal dos Direitos Humanos (DUDH), aprovada pela Assembleia Geral das Nações Unidas em 10 de dezembro de 1948, reconhece a vida privada e a intimidade como direitos humanos, ao dispor que: "Ninguém deverá ser submetido a interferências arbitrárias na sua vida privada, família, domicílio ou correspondência, nem ataques à sua honra e reputação. Contra tais intromissões ou ataques todas as pessoas têm o direito à proteção da lei”. 
No ordenamento jurídico brasileiro, o direito à vida privada e a intimidade estão alinhados no art. 5, inciso $\mathrm{X}$ da $\mathrm{CF} / 88$ e o próprio texto da Carta Magna atribui tipificação diferente ao dispor que "são invioláveis a 'intimidade', 'a vida privada', a honra e a imagem das pessoas, assegurado o direito a indenização pelo dano material ou moral decorrente de sua violação". Contudo, isto não significa que sejam direitos ilimitados, pois, sofrem limitações quando se contrapõem a outros direitos fundamentais. Essas restrições podem ser objetos de uma atuação legislativa ou intervenção judicial (SAMPAIO, 1998).

O art. 21 do Código Civil de 2002, reafirma a inviolabilidade já mencionada na Carta Magna ao dispor que "a vida privada da pessoa natural é inviolável, e o juiz, a requerimento do interessado, adotará as providências necessárias para impedir ou fazer cessar ato contrário a esta norma".

Desse modo, esta concisa gênese histórica aclara que a acepção jurídica de privacidade e de intimidade são recentes e ainda se encontram em processo de transformação no tocante a proteção dos dados pessoais nos meios informáticos e telemáticos devido a evolução da tecnologia na era da sociedade de informação.

\section{ACEPÇÕES TEÓRICAS E DISTINÇÃO ENTRE PRIVACIDADE E INTIMIDADE}

Para realizarmos a distinção entre o direito à intimidade e o direto à privacidade, faz-se necessária primeiramente uma abordagem de alguns conceitos, vez que tanto no ordenamento jurídico brasileiro, não há uma definição peculiar para esses direitos nas respectivas Constituições. Sendo assim, cabe a doutrina realizar o encargo de conceituar estes direitos.

2.1 Conceitos clássicos de direito à privacidade 
Para Roxana Cardoso Borges (2007), no direito brasileiro "as expressões 'direito a privacidade' e 'direito a vida privada' se aproximam da ideia de segredo, de sigilo, de nãopublicidade, de reserva, de direito de estar só, como na doutrina americana".

Nesse sentido, Alessandro Hirata (2017) também preleciona que a concepção de privacidade deve ser interpretada como o "direito de ser deixado só" - right to be let alone, mas acrescenta a necessidade de não interferência pelo Estado na vida do indivíduo.

O conceito de direito fundamental à privacidade, conforme Borges (2007), consiste na proteção do conhecimento alheio o modo de ser da pessoa, como por exemplo, o comportamento religioso, cultural, sexual, os sentimentos, as características e os apelidos conhecidos apenas pelos que participam do círculo familiar e de amizade.

De acordo com a definição clássica, a proteção à vida privada da pessoa natural traduzse como o direito de conduzir a sua vida com o estilo de vida que deseja sem a intromissão e curiosidade de terceiros.

Vale frisar que a pessoa não é só privada, íntima, reservada quando passa a porta da sua morada, corre as cortinas, mesmo em locais públicos, a pessoa continua envolta numa esfera privada. O que cada um é, o que faz, as suas ideias, como se veste só a si diz respeito: eis a esfera privada (NEVES, 1991).

Assim, o direito à privacidade, não se limita apenas a vedação à intromissão de terceiros na vida íntima (dever geral de abstenção), impõe também deveres de caráter positivo, como o dever de solicitar autorização para a inclusão do nome de determinada pessoa em um cadastro de dados ou o dever de possibilitar a correção de dados do mesmo cadastro pelo seu titular a qualquer tempo (SCHREIBER, 2013).

\subsection{Conceitos clássicos de direito à intimidade}

Em sua acepção clássica "o direito à intimidade possui como âmbito de proteção material os aspectos mais interiores ou próximos do indivíduo, os quais formam o que se denomina zona íntima e reservada" (PEREIRA, 2006). 
O direito fundamental à intimidade é variável segundo o momento histórico e pode ser compreendido como o direito mais interior das pessoas, seus pensamentos, ideias, emoções, o âmbito da vida pessoal e familiar diante da intromissão ilegal. Busca-se portanto, a tutela do segredo domiciliar, o profissional e das comunicações telefônicas.

Este direito é uma forma mais restrita em relação à privacidade, como por exemplo, comportamentos que apenas seu parceiro sexual pode saber, a revelação de doença, de remédios que a pessoa usa exibição da resistência e de animais de estimação, entre outras situações.

Apesar desta ampla proteção, é possível que as próprias pessoas disponibilizem gratuitamente ou mediante retribuição monetária algumas informações íntimas, como ocorre na mídia.

Pereira Peres Luño (2001), define a intimidade como expressão do valor jurídico fundamental da dignidade da pessoa humana. Para Hirata (2017) o direito à intimidade "pode ser conceituado como aquele que visa a resguardar as pessoas dos sentidos alheios, principalmente da vista e dos ouvidos de outrem.

Desse modo, o direito à intimidade também é conceituado como o direito que a pessoa humana possui de distanciar indivíduos estranhos de informações ou fatos pessoais que não deseje compartilhar, está relacionada a pessoa em seu momento de solidão. Portanto, o direito à intimidade visa proteger a parte da vida que a pessoa leva quando está distante da observação alheia.

2.3 Diferença entre privacidade e intimidade

Podemos perceber a estreita vinculação entre a privacidade e a intimidade, por esta razão merece destaque a teoria das esferas -Sphärentheorie, para diferenciar estes direitos. Também conhecida como a "teoria dos círculos concêntricos da esfera da vida privada" ou "teoria das esferas da personalidade", esta teoria de origem alemã, criada em 1950 pelos influentes juristas Heinrich Hubmann e Heinrich Henkel. 
Para isso, os inventores utilizaram-se de uma representação em que a esfera da vida privada da pessoa humana se divide, conforme a respectiva densidade, em três círculos concêntricos denominados de Privatsphäre, Intimsphäre e Geheimsphäre (esfera privada, intima e secreta).

A esfera externa, isto é, a de maior amplitude, simboliza a privacidade, abarcando um maior número de vínculos interpessoais e até aqueles mais superficiais, de fatos. Significa o desejo de excluir informações, fatos, hábitos, etc., do conhecimento alheio.

O círculo intermediário, refere-se a intimidades, remete às informações pessoais mais restritas, compartilhadas com algumas pessoas de confiança, ou seja, no âmbito familiar e com os amigos íntimos.

Por fim, a circunferência menor, ou seja, a mais interna engloba apenas o segredo "e que seria vulnerada quando do conhecimento de fatos que deveriam permanecer ignorados"(LUÑO apud PEREIRA, 2006).

São aqueles fatos ou informações que o ser humano não deseja compartilhar e se desejar apenas que seja em situações restritas. Assim, a intensidade dessa tutela jurídica deve variar de forma inversamente proporcional à sociabilidade do comportamento analisado, isto significa que quanto mais interna for a esfera, mais intensa deverá ser a proteção jurídica (HIRATA, 2017).

Assim, o direito à privacidade é mais amplo que o simples direito à intimidade, tendo em vista que o direito à privacidade abrange a intimidade e o sigilo. Assim sendo, a distinção entre o direito à privacidade e o direito à intimidade, é uma questão de abrangência e não uma questão conceitual.

\section{MECANISMOS DE PROTEÇÃO DE DADOS PESSOAIS DE USUÁRIOS DE INTERNET NO BRASIL}

A comunicação em rede transcende fronteiras e alcança países de todo o planeta (CASTELLS, 2005), bilhões de pessoas são usuárias da rede mundial de computadores e assim 
expõem suas vidas nas redes sociais, guardam suas informações na nuvem, usam sites de pesquisa, realizam compras na internet, entre outros.

O problema, surge quando as informações coletadas por empresas públicas ou privadas são utilizadas como instrumentos para a prática de atos ilícitos e até mesmo de controle social por meio dos algoritmos de inteligência artificial que traçam o perfil dos usuários de internet.

Por isso, o direito brasileiro precisou evoluir para acompanhar a evolução das tecnologias de informação e comunicação na sociedade moderna, a fim de assegurar a proteção à privacidade, a inviolabilidade da intimidade e o exercício destes direitos ambientes virtuais.

3.1 Legislações infraconstitucionais e entendimento jurisprudencial quanto ao uso da internet no Brasil

Um acontecimento que simbolizou o pontapé inicial para a criação de uma lei voltada para o cometimento de crimes cibernéticos, foi o "Caso Carolina Dieckmann" que ganhou repercussão nacional quando a atriz teve as suas fotos íntimas divulgadas em um sítio eletrônico por se negar a pagar uma determinada quantia monetária solicitada pelo hacker que invadiu o seu computador. Em razão disso, foi aprovada a Lei $\mathrm{n}^{\circ} 12.737 / 12$, conhecida como "Lei Carolina Dieckmann" que tipificou criminalmente os delitos informáticos.

Assim sendo, aquele que invadir dispositivo eletrônico de outrem quer esteja conectado ou não à internet sem autorização expressa ou tácita do titular do dispositivo ou instalar vulnerabilidades para obter vantagem ilícita, para adulterar ou destruir dados ou informações, comete crime de invasão de dispositivo informático (art.154-A do CP/40).

Também incorre no mesmo crime quem produz, oferece, distribui, vende ou difunde dispositivo ou programa de computador com o intuito de permitir esta prática criminosa $\left(\S 1^{\circ}\right)$.

Posteriormente, a fim de disciplinar princípios, garantias, direitos e deveres para o uso da internet no Brasil, criou-se o Marco Civil da Internet (Lei n ${ }^{\circ}$ 12.965/14) que simboliza uma conquista democrática, já que os temas abordados foram desenvolvidos com o apoio da população antes de se tornar lei. 
Esta lei, fixa que a proteção dos registros de conexão, dados pessoais e conteúdo das comunicações privadas devem atender a preservação da vida privada, da intimidade, da honra e da imagem das partes direta ou indiretamente envolvidas (art. 10). A lei assinala o princípio a proteção à privacidade, mas a inovação no ordenamento jurídico brasileiro foi a criação do princípio a proteção dos dados pessoais (art. $3^{\circ}$, inciso II e III).

Ademais, prevê a proteção de alguns direitos, tais como: Inviolabilidade da vida privada e da intimidade (inciso I do art. $7^{\circ}$ ); Inviolabilidade e sigilo do fluxo de suas comunicações pela internet e das comunicações privadas armazenadas, salvo por ordem judicial (incisos II e III do art. $7^{\circ}$ ); Não fornecimento a terceiros de dados pessoais, aplicações e registros de conexão de internet, salvo mediante consentimento (inciso VII do art. $7^{\circ}$ ) e o consentimento livre e expresso sobre coleta, uso, armazenamento e tratamento de dados pessoais (inciso IX do art. $7^{\circ}$ ).

Apesar de ter sido um grande passo para a proteção dos dados pessoais e das comunicações por internet, algumas questões ainda estavam pendentes e a fim de suprir tais lacunas foi sancionada a Lei n ${ }^{0}$ 13.709/18, intitulada "Lei Geral da Proteção de Dados Pessoais" (LGPD).

Esta lei altera o Marco Civil da Internet e tem como fundamentos: O respeito à privacidade (inciso I do art. $2^{\circ}$ ), dignidade da pessoa humana (inciso VII do art. $2^{\circ}$ ), assim como a inviolabilidade da intimidade, honra e imagem (inciso IV do art. $2^{\circ}$ ).

Além disto, dispõe sobre o tratamento de dados pessoais, inclusive nos meios digitais, por pessoa natural ou por pessoa jurídica de direito público ou privado e tem o objetivo de proteger o direito fundamental de privacidade (art. $\left.1^{\circ}\right)$.

Importa evidenciar que, a Lei $n^{\circ} 13.709 / 18$, aplica-se a qualquer operação de "tratamento realizada no Brasil" (inciso III art. $3^{\circ}$ ), independentemente do lugar de sua sede ou de onde estejam localizados os dados (inciso I do art. $3^{\circ}$ ). A aplicação da legislação brasileira nesta hipótese também foi prevista pelo Marco Civil da internet (art. 11).

Esta lei define como "tratamento" toda operação realizada com dados pessoais, como as que se referem a produção, recepção, coleta, acesso, classificação, utilização, reprodução, transferência, difusão, transmissão, distribuição, processamento, arquivamento, 
armazenamento, eliminação, avaliação ou controle da informação, modificação, comunicação, ou extração (art. $5^{\circ}, \mathrm{X}$ da LGPD).

Outrossim, a LGPD abaliza como conceito de dado pessoal: a informação relacionada a pessoa natural identificada ou identificável, como um dado utilizado para formação do perfil comportamental da pessoa natural, se identificada (art. 12). Assim sendo, os dados pessoais não se resumem apenas ao nome, endereço (físico ou eletrônico de e-mail), estado civil, idade e situação patrimonial.

Considera-se como ponto central da supracitada legislação o "consentimento livre e expresso do titular" para o tratamento de dados pessoais, consagrado como um direito pelo Marco Civil da Internet, conforme evidenciamos anteriormente.

Desse modo, o tratamento de dados pessoais somente poderá ser realizado mediante o fornecimento de consentimento pelo titular (art. $7^{\circ}$, inciso I) que deverá ser realizado por escrito ou por outro meio que demonstre a sua manifestação de vontade (art. $8^{\circ}$, inciso I). Sobretudo, poderá o consentimento emitido pelo titular ser revogado a qualquer tempo.

Além disto, é vedado o tratamento de dados pessoais mediante vício de consentimento $\left(\S 3^{\circ}\right.$ do art. $\left.8^{\circ}\right)$, as autorizações genéricas para o tratamento de dados pessoais serão nulas ( $\S$ $4^{\circ}$ do art. $8^{\circ}$ ) e o titular tem direito ao acesso facilitado às informações sobre o tratamento de seus dados, que deverão ser disponibilizadas de forma clara em atendimento ao princípio do livre acesso $\left(\operatorname{art.} 9^{\circ}\right)$. Todavia, não há necessidade de consentimento para os dados tornados manifestamente públicos pelo titular.

Importa salientar que, antes mesmo da existência da Lei Geral de Proteção de Dados Pessoais (LGPD) dispor o consentimento do usuário de internet como imprescindível para o armazenamento e utilização de dados pessoais, o STJ (Resp. no 1168547/RJ), em 2011, já o anunciava na seguinte afirmativa: "com o desenvolvimento tecnológico, passa a existir um novo conceito de privacidade, sendo o consentimento do interessado o ponto de referência de todo o sistema de tutela da privacidade".

Contudo, há situações pelas quais é preciso que o Estado exerça um determinado controle pessoal sobre os seus administrados, como função de segurança (PEREIRA, 2006). Nesse sentido, foi aprovada a Lei $\mathrm{n}^{\mathrm{o}} 13.853$ de 8 de julho de 2019 que cria a "Autoridade 
Nacional de Proteção de Dados" (ANPD) e inclui alguns dispositivos na Lei Geral da Proteção de Dados. Cabe esclarecer que estas duas legislações só entrarão em vigor em 2020, em razão da vacatio legis.

Com a Lei no $13.853 / 19$, é criada então a Autoridade Nacional de Proteção de Dados (ANPD) como um órgão da administração pública federal (art. 55-A) e poderá ser transformada pelo Poder Executivo em entidade da administração pública federal indireta, submetida a regime autárquico especial e vinculada à Presidência da República ( $§ 1^{\circ}$ do art. 55-A). Esta autoridade terá o encargo de ser o guardião da proteção de dados na internet.

Dentre algumas de suas competências previstas no art. 55-J (incluído na LGPD), destacam-se: promover estudos sobre as práticas internacionais de proteção de dados pessoais e privacidade (inciso VII); promover ações de cooperação com autoridades de proteção de dados pessoais de outros países (inciso IX); implementar mecanismos eletrônicos para o registro de reclamações sobre o tratamento a dados pessoais (inciso XXIV).

Inclusive, fiscalizar e aplicar sanções em caso de descumprimento à LGPD, mediante processo administrativo que assegure o contraditório, a ampla defesa e o direito de recurso (inciso IV).

A LGPD prevê como sanções administrativas aplicáveis pela autoridade nacional: a advertência; multa simples de até $2 \%$ (dois por cento) do faturamento da pessoa jurídica de direito privado no Brasil, no seu último exercício, excluídos os tributos, limitada, no total, a R\$ 50.000.000,00 (cinquenta milhões de reais) por infração (art. 52).

Desta forma, observa-se que o direito brasileiro está passando por um processo de modernização a fim de estabelecer obrigações, assegurar e proteger os direitos (dignidade, privacidade, intimidade, honra e imagem) dos usuários de internet no Brasil, bem como os dados pessoais contidos em dispositivos eletrônicos e na internet.

3.2 O Sigilo dos dados pessoais e comunicações em sistemas de informática e telemática

No direito brasileiro, o sigilo (segredo) dos dados pessoais ou das comunicações em sistemas de informática e telemática, está alinhado em diversos dispositivos legais, tais como: 
no art. $5^{\circ}$, inciso XII da CF/88; no art. $1^{\circ}$ "caput" c/c parágrafo único e no art. 10 da Lei $\mathrm{n}^{\mathrm{o}}$ 9.296/96; no art. 189, incisos I, II e III do CPC/15; Informativo ${ }^{\circ} 944$ do STF, no art. $7^{\circ}$, I, II, III e VII da Lei 12.965/14.

Inicialmente, o art. 5, inciso XII da CF/88 discorre que "é inviolável o sigilo da correspondência e das comunicações telegráficas, de dados e das comunicações telefônicas, salvo, no último caso, por ordem judicial, nas hipóteses e na forma que a lei estabelecer para fins de investigação criminal ou instrução processual penal”.

A posteriori, a Lei $\mathrm{n}^{\circ} 9.296$ de 1996, responsável por regulamentar a parte final do inciso XII, do art. $5^{\circ}$ da CF/88, dispõe a prática da interceptação de comunicações telefônicas, de informática ou telemática, ou a quebra de segredo da Justiça, sem autorização judicial ou com objetivos não autorizados em lei constitui crime com pena de reclusão, entre dois a quatro anos e multa (art. 10).

Ainda sobre o sigilo, importa ressaltar uma novidade trazida no inciso III do art. 189 do CPC/15 (antigo art. 155 do CPC/73), o qual prevê que deve tramitar em segredo de justiça os processos em que constem dados protegidos pelo direito constitucional à intimidade.

A respeito do sigilo dos dados registrados em dispositivo eletrônico, vale enunciar a decisão do STF no RHC 132062/RS julgado em 2016. O caso trata da instauração de procedimento investigatório para averiguar o suposto cometimento do crime de falsidade documental, pelo qual alega-se que o procurador acusado assinou um documento no lugar de seu colega de trabalho de mesma profissão. Então, o Ministério Público Federal requereu a busca, a apreensão e o exame dos computadores utilizados por ambos os procuradores, a fim de apurar em qual equipamento teria sido redigida a peça com a firma alegadamente adulterada.

A defesa impugnou a apreensão e a perícia efetuadas, alegando que implicariam em "acesso a dados" do indiciado fora dos limites fixados no ato judicial, porém o STF entendeu que "descabe invocar a garantia constitucional do sigilo das comunicações de dados quando o acesso não alcança a troca de dados, restringindo-se apenas às informações armazenadas nos dispositivos eletrônicos” (RHC 132062/RS, julgado em 2016). 
De modo recente, a orientação jurisprudencial acima mencionada deixou de ser o entendimento da Corte Suprema, devido a mudança trazida no HC 168052/SP, (rel. Min. Gilmar Mendes, julgamento em 11.6.2019), que proporcionou a criação do Informativo $n^{\circ} 944$ do STF.

Com isso, não prevalece mais a ideia de que só as comunicações são invioláveis e que os dados em si não são objetos de proteção. Dessa forma, os dados contidos em dispositivos eletrônicos passam a ser tutelados pela proteção à intimidade e à privacidade, mesmo questionada a inclusão do acesso a informações.

Salientamos que em caso de colisão entre o direito a intimidade e a informação ou seja entre direitos fundamentais, deve-se aplicar a máxima da proporcionalidade criada pelo Tribunal Constitucional Alemão com o julgamento do caso Lüth e que representa um dos três pilares da Teoria dos Direitos Fundamentais do jurista alemão Robert Alexy. Nas palavras de Lucas Gonçalves da Silva (2006) "a fixação de uma rigorosa hierarquia entre os direitos individuais, acabaria desestruturando-os completamente e desfigurando também a Constituição" (tradução nossa).

Para que essa regra seja utilizada, é preciso passar pelos exames da adequação, necessidade e proporcionalidade em sentido estrito que são subsidiários entre si. Assim, se a medida for adequada (se atingir o fim ou ao menos realizar a promoção para alcança-lo) e necessária (se não houver outra medida fática menos interventiva que atinja o fim quando comparada com outras medidas), poderá ser feito o teste da proporcionalidade em sentido estrito (ponderação dos direitos em colisão pelo julgador que ao final escolherá o direito que tiver mais peso no caso concreto analisado).

Diante do exposto, constata-se a relevância do segredo para a proteção à privacidade e a intimidade da pessoa humana, nos diversos âmbitos da vida privada, em qualquer que seja o momento histórico imperante e acima de tudo diante do tratamento automatizado dos dados pessoais.

3.3 A indenização como meio de prevenção da recorrência de novos crimes 
A violação a vida privada, através de divulgação não autorizada, assim como a intromissão na intimidade de alguém, sem a sua ciência, podem gerar dano moral e/ou material e consequentemente, dever de indenizar.

Quem tem a sua imagem utilizada para fins publicitários sem a devida remuneração tem o direito de ser indenizado em proporção aos lucros obtidos por quem a utilizou, da mesma forma como se tratasse da utilização de qualquer bem patrimonial (SZANIAWSKI, 1993).

Outrossim, existe a possibilidade da pessoa ofendida requerer judicialmente a interrupção da divulgação de fatos que pertencem à sua privacidade, mediante a retirada de circulação de jornais, revistas ou livros, por exemplo, assim como é admissível a exigência da interrupção de intromissão indevida e a tutela preventiva (BORGES, 2007).

Vale frisar que o Marco Civil da internet (inciso I do art. $7^{\circ}$ ), estabelece o direito a indenização por dano material ou moral decorrente da violação da vida privada ou da intimidade dos titulares dos dados pessoais. Enquanto que, a Lei Geral da Proteção de Dados Pessoais assinala que o controlador ou o operador que causar dano patrimonial, moral, individual ou coletivo, em razão do atividade de tratamento, é obrigado a repará-lo.

Como exemplo de indenização por dano moral, temos a recente decisão do STJ (REsp. $\mathrm{n}^{\text {o }} 1445240$ / SP) julgada em 2017, que versa sobre a violação do direito à intimidade e exposição na internet de fotos tiradas em momentos de intimidade em local da festa reservado.

O STJ considerou gravíssima a ofensa cometida contra a autora, e, principalmente, dolosa a atitude do réu, ao propagar as fotos em sites da internet que tinham, em média, 30 (trinta) mil acessos por mês.

O tribunal estipulou o pagamento à autora de uma indenização no valor de R $\$$ 114.400,00 (cento e quatorze mil e quatrocentos reais), o argumento para a condenação possuir um valor tão elevado é que a indenização tem o efeito de desestimular a reiteração de condutas como esta.

Entretanto, existem casos pelos quais as pessoas almejam exatamente o contrário, ou seja, fazem questão de expor a própria vida privada para o público, como ocorre, por exemplo, nos programas de TV big brother Brasil, Casa dos Artistas, entre outros. 
Nestes casos, a supressão da privacidade resulta da expressa vontade de seus participantes que não se incomodam de expor integralmente a privacidade e os expectadores, por sua vez não veem problema em observar à intimidade dos participantes.

$\mathrm{O}$ art. 11 do CC/02, fixa que os direitos da personalidade são intransmissíveis e irrenunciáveis, não podendo o seu exercício sofrer limitação voluntária. Nas palavras Schreiber (2013) quem se apega à letra da lei não compreende como é possível que as imagens sejam veiculadas nos meios de comunicação.

A verdade é que o Código Civil deu à privacidade um tratamento inadequado, porque dedicou um único artigo à matéria e se limitou a um enunciado genérico que não acrescenta nada além do que já está previsto na Constituição Federal (SCHREIBER, 2013).

Esta exposição da privacidade é possível porque antes das imagens serem exibidas a emissora realiza um contrato pelo qual o participante concorda expressamente com as condições de divulgação e os perímetros de invasão da privacidade. Nestes moldes, se o participante vier a ingressar na justiça, a violação ao direito da personalidade não será reconhecida.

Desta forma, compreende-se que não são todos os casos de exposição da privacidade e da intimidade que haverá direito à indenização, pois há situações pelas quais as pessoas fazem questão de expor a sua vida privada, a sua residência e até mesmo alguns segredos pessoais ao público em geral, dentro da legalidade. Vale ressaltar que estas exposições podem ser gratuitas ou onerosas.

\section{A PROTEÇÃO DOS DADOS PESSOAIS NOVAS ACEPÇÕES DA PRIVACIDADE E DA INTIMIDADE DIANTE DAS NOVAS TECNOLOGIAS}

A informática está cada vez mais presente no dia a dia da sociedade contemporânea e em busca de proteger juridicamente a privacidade e a intimidade diante das novas tecnologias, estes direitos passam a transcender a esfera doméstica para alcançar qualquer ambiente onde circulem dados pessoais do seu titular. 
Esses dados pessoais, de acordo com Schreiber (2013), incluem características físicas, código genético, estado de saúde, crença religiosa e qualquer outra informação pertinente à pessoa. Nesse contexto, a privacidade também pode ser definida como o direito ao controle da coleta e da utilização dos próprios dados pessoais.

No atual status de sociabilidade humana na sociedade contemporânea, graças ao desenvolvimento tecnológico dos meios de comunicação, "deve-se entender a privacidade não apenas como não interferência do Estado na vida do indivíduo, mas também como o poder de se reivindicar ao Estado a tutela dessa privacidade, protegendo o indivíduo de terceiros". (GAVISON apud HIRATA, 2017).

As modificação das circunstâncias fáticas e jurídicas, a promulgação de leis posteriores e o significativo desenvolvimento das tecnologias da comunicação, do tráfego de dados e dos aparelhos smartphones levam, contudo, nos dias atuais, a solução distinta, em um típico caso de mutação constitucional (INFORMATIVO No 944 DO STF).

Desta forma, observa-se que as acepções negativas destes direitos fundamentais tornaram-se obsoletas frente ao desenvolvimento tecnológico dos meios de comunicação. Com isso, surge uma nova vertente no direito brasileiro que é a proteção das informações, comunicações eletrônicas e dos dados pessoais dos usuários de internet no Brasil mediante um processo de mutação constitucional.

A Carta de Direitos Fundamentais da União Europeia, consagra em Nice em 07 de dezembro de 2000, dispõe em seu art. 8.1 que " todas as pessoas têm direito à proteção dos dados de carácter pessoal que lhes digam respeito”. Para Pereira (2006) essa carta internacional anuncia o reconhecimento da proteção de dados como um direito fundamental específico e independente do direito fundamental a intimidade, mas ressalta que foi apenas proclamado e não aprovado.

Há quem defenda que a proteção aos dados pessoais seria uma extensão atributo dos direitos à intimidade e privacidade aplicado diante dos tratamentos informáticos dos dados pessoais. Segue esse raciocínio, por exemplo, Rebollo Delgado (2000) ao firmar que "o direito a intimidade informática é uma extensão de um direito ao qual vem complementar e que não é 
outro, mas tão somente o direito a intimidade". O direito a proteção aos dados pessoais é também denominado como autodeterminação informativa (VILLA VERDE, 1994).

Por outro lado, entendemos que a lista dos direitos individuais não é numerus clausus, o que significa que é possível o reconhecimento do direito à proteção dos dados pessoais com status constitucional. Vale ressaltar que tramita no Congresso Nacional a proposta de emenda à Constituição Federal (PEC 17 de 2019) que almeja acrescentar a proteção de dados pessoais, inclusive nos meios como direito fundamental.

O seu texto foi aprovado pelo plenário do Senado não teve voto contrário, tampouco abstenções e segue para a votação na Câmara dos Deputados. Segue o conteúdo da ementa: “Acrescenta o inciso XII-A, ao art. 5\%, e o inciso XXX, ao art. 22, da Constituição Federal para incluir a proteção de dados pessoais entre os direitos fundamentais do cidadão e fixar a competência privativa da União para legislar sobre a matéria” (PEC 19/2019).

Diante do exposto, entende-se que é plausível a inclusão do direito a proteção de dados previsto na Carta de Direitos Fundamentais da União Europeia, por meio de proposta a emenda à Constituição Federal, como um direito fundamental específico e independente da privacidade e intimidade.

\section{CONCLUSÃO}

A privacidade e intimidade são elementos essenciais na sociedade contemporânea, esses direitos não fazem parte de um padrão social, mas se encontram em diferentes níveis a depender da relação afetiva construída entres os seres humanos e o direito foi convocado justamente para proteger esses relevantes valores jurídicos.

Compreende-se que as acepções negativas dadas a privacidade e a intimidade, revelaram-se atrasadas frente ao surgimento das novas tecnologias e a partir daí, a tutela da privacidade da intimidade não pôde permanecer restrita apenas à proteção da vida íntima, pessoal e familiar de cada indivíduo e foi ampliada para a proteção dos dados pessoais, já que a maior parte de nossas informações estão compiladas em dispositivos eletrônicos e na internet. 
Desse modo, as recentes legislações, a doutrina e a jurisprudência, por meio de um processo de mutação constitucional, passaram a entender que a proteção jurídica, da privacidade e da intimidade, engloba também o direito da pessoa humana manter o controle sobre os seus dados pessoais, para evitar que sejam utilizados indevidamente sem o consentimento do titular.

Apesar de existirem diversos catálogos legais que já previam a inviolabilidade a vida privada e a intimidade, compreendemos que as recentes legislações sobre o uso da internet no Brasil (Lei Carolina Dieckmann, Marco Civil da |Internet, Lei Geral da Proteção de Dados e a Lei que cria a Autoridade Nacional da Proteção de Dados) são reflexos de que a sociedade da hiperinformação passa por um processo de transformação fática e jurídica, ensejando primeiramente uma mutação constitucional.

Deste modo, o direito de proteção à privacidade e à intimidade aos dados pessoais da pessoa humana deve se desenvolver na mesma proporção da intervenção na esfera da vida privada e por esta razão é admissível o reconhecimento do direito fundamental à proteção de dados pessoais disponíveis em meios digitais como um novo direito na lista das garantias da Constituição Federal, específico e independente dos direitos à privacidade e à intimidade.

\section{REFERÊNCIAS}


ALEXY. Teoria dos Direitos Fundamentais. Tradução de Luís Virgílio Afonso da Silva. $2^{\circ}$ ed. $4^{\circ}$ reimpr., São Paulo: Malheiros, 2015.

BRASIL. Constituição da República Federativa do Brasil de 1988. Promulgada em 5 de outubro de 1988. Disponível em: 〈http://www.planalto.gov.br/ccivil_03/Leis/L9784.htm>. Acesso em: 10 jul. 2019.

Lei $\mathbf{n}^{\circ} 9.296$ de 24 de julho de 1996. Regulamenta o inciso XII, parte final do art. $5^{\circ}$ da Constituição $\quad$ Federal. Disponível em: <http://www.planalto.gov.br/ccivil_03/LEIS/L9296.htm>. Acesso em: 15 jul. 2019.

Lei 10.406, de 10 de janeiro de 2002. Código Civil. Disponível em: <http://www.planalto.gov.br/ccivil_03/LEIS/2002/L10406.htm>. Acesso em: 15 jul. 2019.

Lei 12.737, de 30 de novembro de 2012. Lei Carolina Dieckmann. Dispõe a tipificação criminal de delitos informáticos. Disponível em: <http://www.planalto.gov.br/ccivil_03/_Ato2011-2014/2012/Lei/L12737.htm>. Acesso em: 15 jul. 2019.

Lei $\mathbf{n}^{\mathbf{0}}$ 12.965, de 23 de abr. de 2014. Marco Civil da Internet. Disponível em: <http://www.planalto.gov.br/ccivil_03/_ato2011-2014/2014/lei/112965.htm>. Acesso em: 15 jul. 2019.

Lei $\mathbf{n}^{0}$ 12.105, de 16 de mar. de 2015. Código de Processo Civil. Disponível em: <http://www.planalto.gov.br/ccivil_03/_Ato2015-2018/2015/Lei/L13105.htm>. Acesso em: 15 jul. 2019.

Lei $\mathbf{n}^{\circ}$ 13.709, de 14 de agosto de 2018. Lei Geral da Proteção de Dados (LGPD). Disponível em: $\quad<\quad$ http://www.planalto.gov.br/ccivil_03/_ato20152018/2018/Lei/L13709.htm>. Acesso em: 15 jul. 2019.

Lei $\mathbf{n}^{\mathbf{0}}$ 13.853, de 8 de julho de 2019. Autoridade nacional de proteção de dado. Disponível em: <http://www.planalto.gov.br/ccivil_03/_ato2019-2022/2019/lei/L13853.htm>. Acesso em: 15 jul. 2019.

$\begin{array}{ccc} & \text { Supremo Tribunal Federal. Informativo no 944. Proteção de dados e inviolabilidade } \\ \text { do } & \text { Disponível } & \text { em: }\end{array}$ $<$ http://stf.jus.br/portal/jurisprudencia/listarJurisprudencia.asp?s1=\%28INTIMIDADE+E+PRI 
VACIDADE+INTERNET\%29\&base=baseInformativo\&url=http://tinyurl.com/y4soq7ck> . Acesso em: 14 jul. 2019.

Supremo Tribunal Federal. RHC 132062/RS. Relator: Min. Marco Aurélio, Relator: Min. Edson Fachin. Brasília, 22 nov. 2016. Pesquisa de jurisprudência. Acórdão. Diário de Justiça Eletrônico. Disponível em: <>. Acesso em: 11 de jun. 2019.

Superior Tribunal de Justiça. REsp. 1168547 / RJ. Relator: Min. Luis Felipe Salomão. Brasília, 07 fev. 2011. Diário de Justiça Eletrônico. Disponível em: < https://scon.stj.jus.br/SCON/jurisprudencia/toc.jsp?livre=INTIMIDADE+PRIVACIDADE+I NTERNET\&b=ACOR\&thesaurus=JURIDICO\&p=true>. Acesso em: 14 jul. 2019.

Superior Tribunal de Justiça. REsp. 1445240/ SP. Relator: Min. Luis Felipe Salomão. Brasília, 10 out. 2017. Diário de Justiça Eletrônico. Disponível em: < https://scon.stj.jus.br/SCON/jurisprudencia/toc.jsp?livre=INTIMIDADE+PRIVACIDADE+I NTERNET\&b=ACOR\&thesaurus=JURIDICO\&p=true>. Acesso em: 14 jul. 2019.

BELTRÃO, Silvio Homero. Direito da personalidade à intimidade. Disponível em:. Acesso em 11 de jul. 2019.

BORGES, Roxana Cardoso Brasileiro. Direito da Personalidade e Autonomia Privada. 2. ed. São Paulo: Saraiva, 2007.

CASTELLS, Manoel; CARDOSO, Gustavo (orgs.). A Sociedade em Rede: do conhecimento a acção política. Imprensa Nacional, 2005.

HIRATA, Alessandro. Enciclopédia Jurídica da PUCSP, tomo II (recurso eletrônico: direito administrativo e constitucional. NUNUS JR., Vidal Serrano (coord). São Paulo: Pontifícia Universidade Católica de São Paulo, 2017.

NEVES, A. Castanheira. Boletim da Faculdade de Direito. Universidade de Coimbra. Bolsa LXVII, 1991.

ORGANIZAÇÃO DAS NAÇÕES UNIDAS (ONU). Declaração Universal Dos Direitos Humanos de $1948 . \quad$ Art. $12 . \quad$ Disponível em: $<$ https://www.unidosparaosdireitoshumanos.com.pt/what-are-human-rights/universaldeclaration-of-human-rights/articles-11-20.html>. Acesso em: 15 jul. 2019. 
PARLAMENTO EUROPEU; CONSELHO DA UNIÃO EUROPEIA. Carta dos Direitos Fundamentais da União Europeia. 07 de dezembro de 2000. Disponível em: <http://www.europarl.europa.eu/charter/pdf/text_pt.pdf>. Acesso em: 17 jul. 2019.

PEREIRA, Marcelo Cardoso. Direito à Intimidade na Internet. Paraná: Juruá, 2006.

PEREZ LUÑO, Antonio Enrique. Derechos Humanos, Estado de Derecho y Constituición. $3^{\circ}$ ed. Madri: Teccnos, 2001.

ROBL FILHO, Ilton Norberto. Direito, Intimidade e Vida Privada. Paraná: Juruá, 2010.

SAMPAIO, José Adércio Leite. Direito à intimidade e à vida privada. Belo Horizonte: Del Rey, 1998.

SCHREIBER, Anderson. Direitos da Personalidade. 2. ed. São Paulo: Atlas, 2013.

SILVA, Lucas Gonçalves da. La Colisión de los Derechos Fundamentales y la Jurisprudencia del Tribunal Brasileño. In: X Congresso Centroamericano y del Caribe de Derecho del Trabajo y la Seguridad Social y II Congresso Nicaraguense de Derecho de Trabajo y de la Seguridad Social, 2006, Managua. El Derecho del Trabajo y los Processos de Integración. Managua: UPOLI, 2006, p. 105.

SILVA, Lucas Gonçalves; MELO, Bricio Luis da Anunciação. A LEI GERAL DE PROTEÇÃO DE DADOS COMO INSTRUMENTO DE CONCRETIZAÇÃO DA AUTONOMIA PRIVADA EM UM MUNDO CADA VEZ MAIS TECNOLÓGICO. Revista Juridica, [S.1.], v. 3, n. 56, p. 354 - 377 , jul. $2019.2316-753 X$ ISSN Disponível em: <http://revista.unicuritiba.edu.br/index.php/RevJur/article/view/3581/371371972>. Acesso em: 20 abr. 2020. doi:http://dx.doi.org/10.21902/revistajur.2316-753X.v3i56.3581.

SZANIAWSKI, Elimar. Direitos de Personalidade e sua Tutela. São Paulo: RT, 1993.

VILLA VERDE, Ignácio Menéndez. "Protección de datos personales, derecho a ser informado y autodeterminación informativa. A propósito de la STC 254/1993". Revista Espanhola de Derecho Constitucional, n. 41, may.ago.1994. 